\title{
A Prospective Study on the Use of Warfarin in the United Arab Emirates
}

\author{
Abdulla Shehab $^{1,2, *}$, Asim Elnour ${ }^{3}$, Abdishakur Abdulle ${ }^{1}$ and Abdul-Kader Souid ${ }^{4}$ \\ ${ }^{I}$ Departments of Internal Medicine, Faculty of Medicine and Health sciences, United Arab Emirates University, Al-Ain, UAE \\ ${ }^{2}$ Department of Cardiology, Al Ain Hospital, Al-Ain, UAE \\ ${ }^{3}$ Department of Pharmacy, Al Ain Hospital, Al-Ain, UAE \\ ${ }^{4}$ Department of Pediatrics, Faculty of Medicine and Health sciences, United Arab Emirates University, Al-Ain, UAE
}

\begin{abstract}
Objectives: The aims of this study were to evaluate adherence of patients and medical staff to warfarin guidelines and assess clinical outcome and predictors of treatment failure.

Methods: This cross-sectional survey involved out- and in-patient subjects receiving warfarin. Patient attentiveness, compliance, co-morbidities, complications, and international normalized ratio (INR) as well as adherence of medical staff to established warfarin treatment guidelines were recorded.

Results: One-hundred-sixty patients were recruited (mean \pm SD age $=54 \pm 1.3$ years; $46 \%$ males; $77 \%$ overweight/obese). Indications for warfarin were atrial fibrillation (35\%), deep vein thrombosis $(28 \%)$, prosthetic heart valve $(20 \%)$ and stroke or dilated cardiomyopathy (12\%). "Warfarin booklets" were made available to $25 \%$ of the patients, and $\sim 80 \%$ of the recipients reported inadequate understanding of its content. INR was strictly monitored in $23 \%$ of the patients; $\sim 70 \%$ never received Information Leaflets; $\sim 88 \%$ were unaware of warning labels; and $\sim 58 \%$ were unaware that over-thecounter medications may affect warfarin. Therapeutic INR $(2.9 \pm 0.2 ; 76$ days) was achieved in $73 \% ; 20 \%$ had high INR $(3.7 \pm 0.1 ; 18.6$ days $)$ and $7 \%$ had low INR $(1.6 \pm 0.1 ; 16.7$ days $)$. Of the patients with high INR, $2.5 \%$ had major bleeding events. Of the patients with low INR, $5 \%$ had thromboembolic events. Poor compliance and co-morbidities were associated with adverse events $(p=0.01)$.

Conclusions: Attentiveness and adherence to warfarin treatment and monitoring guidelines are suboptimal among patients and medical staff. Novel strategies are necessary to alert patients, pharmacists and physicians on the seriousness of warfarin treatment failure.
\end{abstract}

Keywords: Warfarin, international normalized ratio, bleeding, thromboembolism, United Arab Emirates.

\section{INTRODUCTION}

Warfarin is a commonly used anticoagulant, which reduces the occurrence of thromboembolic events (TEE) [1]. The drug, however, is among the top 10 agents linked to serious side effects [2]. It is labeled as a "medication that poses high risks to patients and requires safety controls" [3]. Consistently, bleeding and TEE complications linked to warfarin are relatively common emergency events [2].

Several consensus guidelines have been developed to enhance medical knowledge and competency prior to initiating warfarin treatment [4]. Numerous audits worldwide, however, revealed fundamental deficiencies in many aspects of warfarin therapy [5]. Furthermore, patients on long-term warfarin experience sharp fluctuations in international normalized ratio (INR) due to varying diets, comedications, compliance and alcohol consumption. Thus, strict laboratory monitoring is essential [6].

*Address correspondence to this author at the Departments of Internal Medicine, Faculty of Medicine and Health sciences, United Arab Emirates University, Al-Ain, UAE, P.O. Box: 59262; Al Ain, UAE;

Tel: 00971506161028; E-mail: a.shehab@uaeu.ac.ae
The primary aim of this study was to prospectively monitor adherence of patients and medical staff (nurses, pharmacists and physicians) to the established warfarin therapy guidelines. The secondary aim was to assess the impact of current warfarin practice on patient outcome.

\section{MATERIAL AND METHODS}

This prospective observational cross-sectional warfarin study was conducted in the out- and inpatient facilities of Al Ain Hospital (Al Ain, United Arab Emirates) from December 2009 to December 2010. The study was approved by Al Ain Medical District Human Research Ethics Committee. Informed consent was obtained for each patient.

\section{PATIENTS}

One-hundred-sixty patients on warfarin were recruited. Patients were randomly selected from the Cerner database (800 new patients on warfarin every year) at Al-Ain Hospital. The inclusion criteria were warfarin therapy for $\geq 3$ months, intent-to-treat for $\geq 12$ months, and ability to consent. 


\section{DATA COLLECTION}

A 10-item "warfarin audit questionnaire" was developed and validated by the Drug Utilization and Evaluation Subcommittee (DUES) at Al Ain Hospital. The survey was further validated for content (reliability correlation coefficient $=0.76$ ) by 5 physicians and 2 clinical pharmacists. It was then translated from English to Arabic and vice versa to avoid systematic bias and to ensure uniformity of approach. The Arabic version was used when a patient was unable to understand English.

The questionnaire was administered by trained pharmacists and nurses. The items included perception of warfarin, knowledge on warfarin clinical use, warfarin regimen, compliance, INR profile, indication for warfarin use, bleeding history, possession of the Yellow/ Blue oral anticoagulation therapy booklet, comprehending the booklet content, need to show the booklet when collecting warfarin, concurrent diseases, co-medications (including over-thecounter drugs, prescriptions, vitamins, dietary supplements and traditional medicine), and dietary vitamin $\mathrm{K}$ intake. Patients were also asked about the advice on dose changes, INR results, provision of Patient Information Leaflet, warfarin label (e.g., stating "warfarin must be taken in accordance with their latest INR blood test") and complications (e.g., bleeding and TEE).

\section{ANALYSIS}

Associations between warfarin dose, age, gender, bodymass-index, indications, co-morbid conditions and targeted INR were evaluated by Pearson correlation test and significance by analysis of variance (ANOVA). Linear regression analysis was used to model relationships of INR target with other variables. Variables from univariate statistical tests were entered into multiple stepwise regression analysis. Statistical analyses were performed using SPSS for Windows, version 18.0 software (SPSS, Chicago, IL). A significant difference (two-tailed) was defined as $\mathrm{p}<0.05$.

\section{RESULTS}

\section{Patient Characteristics}

Patient age (mean $\pm \mathrm{SD}$ ) was $54 \pm 1.3$ year, $46 \%$ were males and $77 \%$ were overweight/obese (BMI $>30 \mathrm{~kg} / \mathrm{m}^{2}$ ). Warfarin was given for atrial fibrillation (35\%), deep vein thrombosis $(28 \%)$, prosthetic heart valve $(20 \%)$, and stroke or dilated cardiomyopathy (12\%), Table 1 . None of the patients reported a use of aspirin, non-steroidal antiinflammatory drugs, high-dose penicillin or moxolactam (all known to increase the risk of warfarin-associated bleeding) [7].

\section{INTERVIEW QUESTIONNAIRE}

Warfarin booklets were made available to only $25 \%$ of the patients, and $\sim 80 \%$ of the recipients reported inadequate understanding of its content. Similarly, $\sim 80 \%$ were never asked to show their booklet when collecting warfarin. INR was strictly monitored in only $23 \%$ of the patients. Moreover, $\sim 70 \%$ never received Patient Information
Table 1. Patient Characteristics $(n=160)$

\begin{tabular}{|c|c|c|c|}
\hline Parameters & Frequency (\%) & Mean INR & $p$ \\
\hline \multicolumn{4}{|l|}{ Age Group (Years) } \\
\hline 17 to 39 & $35(21.9)$ & 2.7 & \multirow{4}{*}{0.001} \\
\hline 40 to 59 & $68(42.5)$ & 2.7 & \\
\hline 60 to 79 & $47(29.4)$ & 2.6 & \\
\hline$>80$ & $10(6.2)$ & 2.8 & \\
\hline \multicolumn{4}{|l|}{ Gender } \\
\hline Male & $73(45.6)$ & 2.7 & \multirow{2}{*}{ insignificant } \\
\hline Female & $87(54.4)$ & 2.8 & \\
\hline \multicolumn{4}{|l|}{ Nationality } \\
\hline Arabs & $63(39.4)$ & 2.5 & \multirow{4}{*}{ insignificant } \\
\hline Emiratis & $47(29.4)$ & 2.4 & \\
\hline Asians & $35(21.8)$ & 2.6 & \\
\hline Others & $15(9.4)$ & 2.5 & \\
\hline \multicolumn{4}{|l|}{ Marital status } \\
\hline Married & $131(81.9)$ & 2.6 & \multirow{2}{*}{ insignificant } \\
\hline Unmarried & $29(18.1)$ & 2.7 & \\
\hline \multicolumn{4}{|l|}{ BMI $\left(\mathrm{kg} / \mathrm{m}^{2}\right)$} \\
\hline$\leq 25$ & $37(23.1)$ & 2.5 & \multirow{3}{*}{ insignifican } \\
\hline$>25$ to $<30$ & $51(31.9)$ & 2.4 & \\
\hline$>30$ & $72(45.0)$ & 2.6 & \\
\hline \multicolumn{4}{|l|}{ Indications } \\
\hline Atrial fibrillation & $56(35.0)$ & 2.7 & \multirow{5}{*}{0.002} \\
\hline Deep vein thrombosis & $45(28.1)$ & 2.6 & \\
\hline Prosthetic heart valve & $32(20.0)$ & 3.1 & \\
\hline $\begin{array}{r}\text { Stroke and } \\
\text { cardiomyopathy }\end{array}$ & $20(12.5)$ & 2.4 & \\
\hline Pulmonary embolism & $7(4.4)$ & 2.8 & \\
\hline
\end{tabular}

$\mathrm{INR}=$ international normalized ratio; $\mathrm{BMI}=$ body mass index.

Leaflets; $\sim 88 \%$ were unaware of warning labels indicating "warfarin must be taken in accordance with the latest INR result"; and $\sim 58 \%$ were unaware that over-the-counter medications may affect warfarin therapy (Table 2).

\section{INR}

Sustained therapeutic INR (mean $\pm \mathrm{SD} ; 2.9 \pm 0.2$ ) was documented in $73 \%$ of the patients (duration $=76.1 \pm 2$ days). High INR $(3.7 \pm 0.09)$ was noted in $20 \%$ of the patient (duration $=18.6 \pm 3$ days) and low INR $(1.6 \pm 0.12)$ in $7 \%$ (duration $=16.7 \pm 2$ days). Patients received advices to change warfarin dosing by physicians $(61 \%)$, nurses $(23 \%)$ and pharmacists $(16 \%)$. 
Table 2. Interview Questionnaires

\begin{tabular}{|c|c|c|}
\hline \multirow[b]{3}{*}{ Question Statements } & \multicolumn{2}{|c|}{ Patient's Response } \\
\hline & Yes & No \\
\hline & N (\%) & N (\%) \\
\hline 1) Do you currently have a copy of the Yellow/ Blue Oral Anticoagulation Therapy (warfarin) Booklet? & $40(25.0)$ & $120(75.0)$ \\
\hline 2) If you have the booklet, do you fully understand its contents? & $31(19.4)$ & $129(79.6)$ \\
\hline 3) Were you asked to show your booklet when you collected your warfarin? & $33(20.6)$ & $127(79.4)$ \\
\hline 4) Are you having regular INR to ensure the dose is appropriate? & $123(76.9)$ & $37(23.1)$ \\
\hline 6) When warfarin is issued, do you always receive a Patient Information Leaflet? & $47(29.4)$ & $113(70.6)$ \\
\hline 7) When warfarin is issued, is there always a label stating: "it must be taken in accordance with your latest INR test"? & $20(12.5)$ & $140(87.5)$ \\
\hline $\begin{array}{l}\text { 8) Are you aware that some medications, which can be purchased over the counter without prescription, may also } \\
\text { affect your warfarin? }\end{array}$ & $68(42.5)$ & $92(57.5)$ \\
\hline
\end{tabular}

The INR; international normalization ratio, level was explained to the patients.

Table 3. Significant Predictors of “Achieving Sustained Therapeutic International Normalized Ratio (INR)” on Multivariate Analyses

\begin{tabular}{|l|c|c|c|}
\hline Variable Entered (Step-wise) & Confidence Interval & Odds Ratio & $\boldsymbol{p}$ \\
\hline \hline Age & -2.3 to -0.34 & -1.47 & 0.015 \\
\hline Indication for warfarin & -4.5 to -1.3 & -2.46 & -3.12 \\
\hline Warfarin dose & -4.3 to -1.8 & -1.67 & 0.018 \\
\hline Co-morbid status & -2.1 to -0.57 & -2.63 & 0.042 \\
\hline Compliance & -3.9 to -1.46 & 0.037 \\
\hline
\end{tabular}

\section{COMPLICATIONS}

Emergency visits or hospitalizations occurred in $22 \%$ of the patients, mainly for TEE $(5 \%$, INR $=1.6 \pm 0.12)$, major bleeding $(2.5 \%, \mathrm{INR}=3.7 \pm 0.09)$, minor bleeding $(5.2 \%$, $\mathrm{INR}=3.3 \pm 0.17)$ and unrelated causes (9.3\%). Abnormal bleeding was reported frequently (all with high INR), including hematemesis $(25.3 \%, \mathrm{INR}=3.8 \pm 0.06)$, cuts associated with shaving $(21.8 \%$, INR $=3.4 \pm 0.07)$, gum bleeding $(19.9 \%$, INR $=3.6 \pm 0.04)$, wound bleeding $(14.6 \%$, INR $=3.7 \pm 0.04)$, melena $(11.3 \%$, INR $=3.4 \pm$ $0.09)$ and other bleeding sites $(7.1 \%$, INR $=3.6 \pm 0.09)$.

\section{PREDICTORS}

Multivariate analyses revealed younger age, lower warfarin dosing, less co- morbid conditions, and better compliance were independent predictors of achieving a sustained therapeutic INR (Table 3).

\section{DISCUSSION}

The primary objective of this study was to assess the quality of care for patients receiving hospital-initiated (in- and out-patient) warfarin therapy. The secondary objective included assessing patient attentiveness to critical information on the use of warfarin. The study also examined whether our tertiary-care hospital effectively implemented the warfarin therapy guidelines. These guidelines were established to assure patients continuously receiving appropriate warfarin dosing based on INR and other criteria, such as specific indications for warfarin and assessment of associated risk factors [8]. The guidelines emphasized that patients on warfarin should have detailed records of relevant clinical information and INR values in a booklet. Unfortunately, such data were missing for the majority of patients.

Only $25 \%$ of the patients had warfarin therapy booklets, and most of the recipients admitted inadequate understanding of its content. This finding suggests that medical staff who prescribed warfarin did not thoroughly explain necessary facts to patients. Consistently, most patients were never asked to show their booklets, had no discussion pertinent to the booklet content, and did not comprehend the importance of regular INR measurements. Over $50 \%$ of the patients were unaware that certain over-thecounter medications may adversely affect warfarin therapy.

Thus, the data clearly show healthcare providers do not strictly adhere to the recommended warfarin therapy guidelines. This observation could, in part, reflect dependency of many physicians on electronic records to check INR and adjust dosing with minimum patient contact.

Regarding therapeutic INR, the results show that $27 \%$ of the patients never attained acceptable target levels. Of note, sustained therapeutic INR was obtained in $76 \%$ of the days. 
INR in the remaining days was either high or low, predisposing to bleeding or thrombosis, respectively. This finding is consistent with other reports showing difficulty in maintaining therapeutic INR $>70 \%$ of the days [5]. Similar to another study, $\sim 5 \%$ of the patients developed TEE [9]. The bleeding episodes, on the other hand, were much more frequent then found in other studies [10], which raised a major concern about the safety of warfarin.

\section{CONCLUSIONS}

Adherence to warfarin treatment and monitoring guidelines is crucial. Patients' attentiveness was found to be limited. Novel programs, such as teaching films and group discussions can be used as vehicles to deliver useful information. Prescribing warfarin should be strictly coupled to adequate patient education.

\section{ACKNOWLEDGEMENTS} 01-10).

Supported by a grant from UAE University (1609-08-

\section{CONFLICT OF INTEREST}

No conflict of interest.

\section{REFERENCES}

[1] Fuster V, Rydén LE, Cannom DS, et al. ACC/AHA/ESC 2006 guidelines for the management of patients with atrial fibrillationexecutive summary: a report of the American College of
Cardiology/American Heart Association Task Force on Practice Guidelines and the European Society of Cardiology Committee for Practice Guidelines (Writing Committee to Revise the 2001 Guidelines for the Management of Patients with Atrial Fibrillation). Eur Heart J 2006; 27:1979-30.

[2] Wysowski DK, Nourjah P, Swartz L. Bleeding complications with warfarin use: a prevalent adverse effect resulting in regulatory action. Arch Intern Med 2007;167: 1414-9.

[3] Jim S. Building a safer NHS for patients: improving medication safety. Publications policy and guidance 2004; Available from: http://www.dh.gov.uk/en/Publicationsandstatistics/Publications/Pu blicationsPolicyAndGuidance/DH_4071443.

[4] Keeling D, Baglin $\mathrm{T}$, Tait $\overline{\mathrm{C}}$, et al. Guidelines on oral anticoagulation with warfarin - fourth edition. Br J Haematol 2011; 154:311-24.

[5] Lader E, Martin N, Cohen G, et al. Warfarin therapeutic monitoring: is $70 \%$ time in the therapeutic range the best we can do? J Clin Pharm Ther 2011; doi:10.1111/j.1365-2710.2011.01324.x [Epub ahead of print].

[6] Prasad V, Kaplan RM, Passman RS. New frontiers for stroke prevention in atrial fibrillation. Cerebrovasc Dis 2012; 33:199-208.

[7] Vitry AI, Roughead EE, Ramsay EN, et al. Major bleeding risk associated with warfarin and co-medications in the elderly population. Pharmacoepidemiol Drug Saf 2011; 20:1057-63.

[8] Hirsh J, Dalen J, Anderson DR, et al. Oral anticoagulants: mechanism of action, clinical effectiveness, and optimal therapeutic range. Chest 2001; 119:8S-21S.

[9] Chiquette E, Amato MG, Bussey HI. Comparison of an anticoagulation clinic with usual medical care: anticoagulation control, patient outcomes, and health care costs. Arch Intern Med $1998 ; 158: 1641-7$.

[10] Gulløv AL, Koefoed BG, Petersen P. Bleeding during warfarin and aspirin therapy in patients with atrial fibrillation: the AFASAK 2 study. Atrial Fibrillation Aspirin and Anticoagulation. Arch Intern Med 1999; 159:1322-8. 